\title{
Imaginarios urbanos en el Gran Santiago: huellas de una metamorfosis
}

\begin{abstract}
From a reading, between the lines, of the book Santiago en EURE. Huellas de una metamorfosis metropolitana: 1970/2000, this article reflects on the urban imaginaries of Santiago presented over the last thirty years. Beyond the declared objectives and conceptual frameworks of the authors, it can be noted that aspects of these urban imaginaries filter into and are expressed in each of the selected texts. The analysis focuses on three principal imaginary narratives for the city of Santiago: one that persists and resists over time, the imaginary of city/country, and two others that through their incomplete metamorphosis are never resolved by the inhabitants of the city: the imaginary of the integrated city/fractured city, and the imaginary of the village city/world city.
\end{abstract}

Keywords: urban imaginary, city, Santiago de Chile

\section{Resumen}

A partir de una lectura entrelíneas del libro Santiago en EURE. Huellas de una metamorfosis metropolitana: 1970/2000, se reflexiona sobre los imaginarios urbanos en Santiago en estos últimos treinta años. Más allá de los objetivos y marcos conceptuales de los autores, se afirma que siempre e inevitablemente, algo de estos imaginarios urbanos se filtra y expresa en cada uno de los textos escogidos. El análisis se detiene en tres grandes relatos imaginarios en torno a la ciudad de Santiago: Uno que persiste y resiste a los tiempos, el imaginario de ciudad/país. Y otros dos que en su metamorfosis incompleta anuncian las contradicciones nunca resueltas de los habitantes de esta ciudad de Santiago: El imaginario de ciudad integrada / ciudad trizada. El imaginario de ciudad aldea / ciudad mundo.

Palabras claves: imaginario urbano, ciudad, Santiago de Chile. 


\section{Los imaginarios y la imaginación ${ }^{1}$}

Antes de comenzar la lectura sobre los imaginarios en la ciudad de Santiago, quisiera señalar que por imaginarios sociales se entenderá aquella manera compartida - de intensidad variable en nuestra individualidad moderna- de representar el espacio y el tiempo (Baeza, 2000).

Los imaginarios, como matrices de sentidos que son, se sitúan en la difusa frontera de lo real y lo imaginado: lo deseado, lo perdido, lo que no se tiene. Pero justamente, porque hablan de lo perdido y lo deseado, los imaginarios -expresiones simbólicas- siempre suponen un ánimo de visualizar lo invisible (Castoriadis, 1998). El ejercicio de imaginar es, entonces, una intención dirigida a un objeto ausente. En el acto de imaginar, ejercicio de la conciencia por definición, plantea Jean-Paul Sartre (1986), se trata de traer al presente ${ }^{2}$ un objeto que sabemos que no está. La aprehensión del objeto no puede, entonces, sino hacerse sobre la base de imágenes que le otorgarán un nuevo sentido.

En consecuencia, señala Sartre (1986), la imagen es un acto que busca en su corporeidad un objeto ausente o inexistente, a través de un contenido físico o psíquico que no se da completamente sino a título de representante análogo del objeto buscado. No podemos, sin embargo, estudiar separadamente la imagen mental de su objeto, no hay un mundo de las imágenes y un

* Este artículo se basa en la presentación oral del libro Santiago en EURE. Huellas de una metamorfosis metropolitana: 1970/2000 realizada en octubre del 2007, en el Instituto de Estudios Urbanos de la Pontificia Universidad Católica de Chile. Algunas referencias aluden a resultados de investigaciones de la autora sobre identidades urbanas en Santiago (Fondecyt 1050031, Fondecyt No 1020318, Fondecyt No 1050171). E-mail: fmarquez@academia.cl.

Aunque la iconografía ha sido el soporte privilegiado para los estudios de los imaginarios, este artículo se vale solo de los textos; se asume el planteamiento de Georges Duby (1972) cuando habla de un imaginario en tanto imagen que se lee y visualiza en los textos, la literatura, los periódicos; esto es, la palabra escrita. Realizar cruces y preguntas entre lo escrito, lo oral y la imagen es una tarea que quedará pendiente.

Las citas de J.P. Sartre corresponden a una traducción libre del francés. mundo de los objetos. Los dos mundos, el imaginario y el real, se constituyen por los mismos objetos; solo la agrupación y la interpretación de estos objetos varían. La definición del mundo imaginario como el universo real resulta de una actitud de la conciencia.

Para nuestros propósitos, lo más importante es que el acto de la imaginación tiene siempre algo de acto mágico: "Es un encantamiento destinado a hacer aparecer el objeto sobre el cual se piensa y se desea, de manera tal que se pueda tomar posesión de él. Hay siempre en este acto algo de imperioso y de infantil, un rechazo a considerar la distancia, las dificultades. Pero el objeto en imagen es, y permanecerá siempre, un irreal..." (Sartre, 1986: p. 5-30).

\section{Los imaginarios sociales}

Los imaginarios individuales, sin embargo, no son solo ejercicio de la conciencia solitaria; ellos pasan a ser imaginarios sociales porque el hombre ha de establecer relaciones en su existencia (Castoriadis, 1998). Los imaginarios son sociales porque, en el marco de las relaciones entre los hombres, se producen condiciones históricas y sociales favorables para que determinados imaginarios sean colectivizados. Los imaginarios sociales, a diferencia de los individuales, requieren ser institucionalizados y legitimados socialmente.

Por ende, los imaginarios jamás -a pesar de su relativa autonomía- están exentos de historicidad. Cada gran época y cada lugar, entendido como el lugar antropológico (Augé, 1992), contiene uno o varios paradigmas imaginarios (Baeza, 2000). Los imaginarios se ubican en esa frontera de lo deseado y lo perdido, de lo visible y lo invisible; y es por eso que también signan las maneras de enfrentar la vida en sociedad, es decir, llevan la huella de la historicidad.

Si pensamos en los espacios urbanos de lo público, las plazas, las carreteras, los monumentos, en la ciudad de la materialidad, veremos que siempre habrá un imaginario que la construye y acompaña. Los imaginarios marcan la ciudad y, por ende, la manera de percibirla, de moverse en ella y habitarla. 
Preguntarse por estos imaginarios de la ciudad exige, por tanto, preguntarse por estas construcciones fundacionales que contribuyen o contribuyeron a hacer inteligible la experiencia de vida en la ciudad. Los imaginarios en estos términos, nos hablan siempre de utopía y de deseo (Silva, 1996). Nos hablan de cómo los que habitan y también los que escriben sobre la ciudad, imaginan e inventan formas de vida urbana para crear su ciudad. La ciudad imaginada, la ciudad subjetiva, así como habla de utopías y de una ciudad ideal a la manera como lo hicieron en su tiempo Campanella o Tomás Moro... también nos conduce a un encuentro con los afectos y los sentidos de la ciudad vivida y proyectada.

En síntesis, la ciudad siempre tiene que arreglárselas con la construcción de imaginarios (Silva, 1996) que actúan como matrices de sentido. Son cartas de navegación, que fundamentan la acción de los sujetos y actores sociales, enriquecen y complejizan la razón, haciéndola deambular entre la realidad y la fantasía. El imaginario se presenta, no como una gramática ordenada de inteligibilidad del universo, sino como una composición relativamente libre e irrefutable, en la medida que no ha de rendir cuentas a ningún tipo de racionalidad. ${ }^{3}$ Lo imaginario tiene relación con la creencia y la trama esencial del creer (Baeza, 2000).

\section{Los imaginarios, hipertrofia y metamorfosis}

Así como los imaginarios nos hablan de sueños y visiones de mundo, ellos también organizan la memoria. Pero más que testimoniar lo que se recuerda, los imaginarios ilustran la nostalgia contribuyendo a la hipertrofia de la memoria como fuente de conocimiento histórico ${ }^{4}$. En este paso de

Resulta interesante la presentación de Alexander Galetovich al libro Santiago, dónde estamos y dónde vamos (CEP, 2005), en la que señala que "quizás sea hora de averiguar qué tan cierto es lo que creemos" sobre la ciudad. Para ello el libro se propone diagnosticar, medir, evaluar y discutir la veracidad de nuestras creencias sobre esta ciudad de Santiago. Por cierto, las creencias también dialogan con las cifras, pero, como los imaginarios, el curso y la forma que ellas tomen, no son nunca asunto de la razón.

Rojas (2003) ilustra esta condición del imaginario a través de la autobiografía de Isabel Allende, Mi país inventado (2003): "Tengo una imagen romántica de un Chile congela- la memoria a la imaginación, la certeza y la ilusión se entremezclan, y generan así más que un relato, una imagen que a menudo amplifica y transforma el acontecer. Es por ejemplo, la nostalgia que responde a esta hipertrofia de la memoria colectiva, del pasado rural y comunitario... Y donde el acontecimiento termina por desdibujarse o sufrir una metamorfosis tal, que asombra. En este proceso, la memoria rompe su pacto con el pasado y pasa a la alquimia ${ }^{5}$ de la imaginación. La imaginación, liberada de la fidelidad al pasado, ocupa finalmente el lugar de la memoria.

En este paso de la memoria a la imaginación, por cierto hay olvido. El olvido no significa no recordar, ni borrar la historia, significa simplemente el paso de la memoria literal a la memoria simbólica, para reinstalar por ejemplo, un imaginario nacional unificador que permita reconstituir el cuerpo social (Rojas, 2006) y la comunidad imaginada (Anderson, 1991).

El punto más interesante-desde una perspectiva antropológica- es preguntarse cómo y bajo qué condiciones en nuestra ciudad se produce la socialización y la metamorfosis de estos imaginarios y representaciones. Ciertamente hay condiciones sociales e históricas más favorables que otras para que determinados imaginarios sean colectivizados e instituidos socialmente. En una sociedad de la desigualdad y hegemonía del mercado como la nuestra, la apropiación y manipulación de imaginarios sociales a menudo se impone. Aun así, el imaginario triunfante no siempre fagocita toda la diversidad de imaginarios sociales. Nuestras ciudades, diría Georg Simmel (1998), por definición son escenarios de coexistencia de culturas

do a comienzos de la década de los setenta... He armado la idea de mi país como un rompecabezas, seleccionando aquellas piezas que se ajustan al diseño e ignorando las demás... ese país mítico que de tanto añorar ha reemplazado al país real ... me inquieta esta tendencia a transformar la realidad, a inventar la memoria, porque no sé cuán lejos me puede conducir".

La alquimia, señala J. Bengoa a propósito de Carl Jung, se ocupa de encontrar el germen de la unidad, de la totalidad, que está escondido en el caos. La alquimia fue el intento, precientífico quizás, de buscar la unión de los contrarios. La esencia de la conciencia en cambio, es la diferenciación. Para realizar el estado de conciencia es necesario separar los contrarios, separarlos a los unos de los otros. 
e identidades diversas; siempre habrá lugar para que nuevos imaginarios irrumpan en los espacios residuales que contiene la ciudad.

Como composiciones relativamente libres, los imaginarios sociales constituyen universos simbólicos que gozan de autonomía con respecto a la sociedad porque no se someten a lógica ni funcionalidad alguna. Por el hecho de no ser una simple y pura representación de lo pre-existente, los imaginarios sociales logran entonces escapar a los determinismos espacio-temporales (Baeza, 2000). Pero el imaginario dominante o hegemónico también dejará fuera espacios que podrán servir de detonantes para el nacimiento y despliegue de otros imaginarios.

En esta doble cara de los imaginarios sociales, como composiciones de la memoria hipertrofiada y como composiciones en permanente metamorfosis, se sitúa el análisis de los tres grandes relatos imaginarios en torno a la ciudad de Santiago. Uno que persiste y resiste a los tiempos, el imaginario de ciudad / país. Y otros dos que en su metamorfosis incompleta anuncian las contradicciones nunca resueltas de los habitantes de esta ciudad de Santiago: El imaginario de ciudad integrada/ ciudad trizada, y el imaginario de ciudad aldea/ ciudad mundo.

\section{El imaginario de la ciudad / país: Santiago es Chile}

$Y$ es que Santiago, dentro de su aparente simplicidad, es un caos de sensaciones y visiones diversas. Ya lo hemos visto: el chileno central es la incógnita, escándalo y gloria de una región que ha llegado a identificarse-tal vez injustamente-con el nombre de Chile.

\section{B. Subercaseaux, Chile} o una loca geografía, 1940.

Cuenta Armando de Ramón, que en los tiempos de la conquista, los indios rebeldes de Chile pronto se dieron cuenta del papel que comenzaba a desempeñar la ciudad de Santiago en el proceso de la dominación castellana. El propio caudillo Lautaro había entendido que la destrucción de Santiago, implicaba el fin de todo el Reino. Lo mismo pensaban los conquistadores cuando afirmaban que de Santiago se obtenía "toda la sustancia que hay en este Reino". Asimismo, cuando las ciudades del Sur caían abatidas o la sublevación era inminente, sus habitantes terminaban por refugiarse en Santiago. Asistimos, nos señala el historiador, al nacimiento de un estereotipo que perdurará a través de los siglos, cualquiera que fuesen los cambios en las condiciones de vida.

Sin duda que el origen de esta leyenda, de este imaginario, estuvo fundado en el doble papel que desempeñaba Santiago en el siglo XVI, frente a las demás ciudades del país. Es decir, Santiago como proveedora y sostenedora de la conquista y lugar de refugio, recreo y descanso, se convirtió en el arquetipo de la tranquilidad y la paz, el lugar más seguro del Reino. La ubicación de Santiago era reconocida por los viajeros como una de "las más convenientes y deleitosas" que pueda imaginarse. Se había generado así un proceso que no se interrumpiría hasta nuestros días. Por ser más rica, la ciudad de Santiago atraía población. Por ser más poblada, atraía más capitales y comercio. Por ser el primer centro comercial del Reino, la ciudad atraía riqueza y población. Ello contribuyó a que se transformara, para el resto del país (y para ella misma) en un modelo al cual todos miraban, imitaban y querían hacer suyo (De Ramón, 2000: p. 33-34).

Qué duda puede caber acerca de que la tendencia a la concentración demográfica en la Región Metropolitana persiste. Santiago continúa siendo la gran ciudad del país, muy superior al resto de las ciudades en magnitud demográfica, en poder económico, en poder político y en poder o capital cultural (De Mattos, 2003; 2005). Contrariamente al discurso descentralizador, en Santiago se reconoce una tendencia histórica a la concentración de actividades y capital.

"Es corriente en Chile que se eche la culpa de la creciente concentración de población y actividades económicas a los vicios del sector privado. Una explicación mucho más simple sería, en cambio, decir que el atractivo de Santiago como localización se debe fundamentalmente a la centralización del poder de toma de decisiones del gobierno" (Friedmann \& Necochea, 2005: p. 36). 
En el imaginario colectivo, Santiago es, y ha sido siempre, Chile. Para el migrante que busca de una mejor vida, para el campesino en busca de trabajo o para el empresario vinculado a la economía global, Santiago es la ciudad/país, la ciudad de los césares 6 , la ciudad de las oportunidades. De allí un imaginario que aunque habla de promesas y deseos, irremediablemente se estrella con la evidencia de un orden social centralizador y excluyente...

La ciudad ideal es a su vez la ciudad invisible que cada uno lleva consigo, una nostalgia y un imperativo de realización de otro orden social. Orden social cuyas formas son tantas como los imaginarios de sus agrimensores. Pero en un punto existió y existe consenso: Es en Santiago, donde se sitúa el cardus y el decumanus de la nación. Santiago templum, en donde se cobijan las riquezas y los secretos de esta angosta y larga franja de tierra, que es Chile.

\section{El imaginario de la ciudad integrada / la ciudad trizada}

"En Santiago, las clases acomodadas llevan una vida minima en relación a la inmensa masa del pueblo. Me atrevería a decir que, urbanisticamente llevan una vida acorralada... El pueblo rodea todo, independientemente de lo que ahi se hace; sin importarle nada; enteramente 'chez lui'; ajeno a la vida burguesa que ni siquiera desprecia. La ignora simplemente, o la tolera a título de injerto".

\section{B. Subercaseaux, Chile o una loca geografía, 1940.}

Conforme lo revelan nuestras novelas (ver Franz, 2001; Merino, 2005), el mito de la Ciudad de los Césares reaparece con fuerza en el Santiago del primer centenario -ilustrado, rico, triunfal-, sustentado por un mito de orden político no discutido. Urbe armoniosa que aún en el alba del siglo

\footnotetext{
La ciudad encantada de los césares en las pampas patagónicas toma cuerpo con los relatos sobre el destino de los sobrevivientes de las primeras colonias españolas en el sur de Chile. En 1599, los pocos españoles que se salvaron del asalto de los mapuches, escaparon al Sur y desde Chiloé se internaron a la Patagonia, donde comienza esta leyenda e imaginario.
}

XX podía ser reconocida como una Casa Grande (Orrego Luco, 1973), imagen de una comunidad que celebra unida la dicha de una continuidad histórica armoniosa. Santiago, ciudad muy leal y pacífica, que si se desprende de su apatía colonial, lo hace solo para celebrar con el regocijo de las viejas ciudades españolas. Una ciudad tradicional, pero también abierta a esa confusión democrática de la muchedumbre. El relato se empeñaba entonces en preservar un imaginario de ciudad homogénea que se deseaba hermosa, rica y feliz; una ciudad soñada (Franz, 2001).

Pero junto a esta ciudad soñada, "hay otra historia aún, que pasa por las subjetividades, más difícil e inasible, pero no por eso menos necesaria. En una sociedad radicalmente escindida como es la de Santiago... esta historia tiene dos vertientes: la de la sociedad establecida, de la gente decente, y la de los sectores populares, los rotos... Todo esto define a sus protagonistas, los moldea y transforma, y constituye la trama de una historia de lentas conformaciones, de largas transformaciones, de testimonios esfumados y silencios prolongados" (Romero, 2005: p. 261).

Es la ciudad de los pobladores, de los sin casa, de los marginales que en Santiago constituían, al mismo tiempo que una experiencia única de la lucha política, la organización urbana y el pretexto constante para una mitología multiforme (CIDU, 2005). Eran los tiempos de las ocupaciones y de las tomas de terrenos y del ideario (y no solo imaginario) de una ciudad para todos, que irrumpía y rompía así con la ciudad propia y la ciudad bárbara de Vicuña Mackenna. Es la historia construida al calor de la imagen que surge de la acción colectiva de los pobladores, como actores y movimiento social.

Movimiento y confusión democrática que desdibuja y desordena la ciudad controlada y ordenada, y con ella el imaginario del peligro y del temor al otro. "¿Son guaridas de lumpen y caldo de delincuencia, como pretende la prensa reaccionaria? O, simplemente, ¿son un medio de presión de las masas urbanas chilenas por obtener el derecho de pisar un suelo propio?" (CIDU, 2005: p. 341). El desconcierto y también el entusiasmo de los intelectuales por estos movimientos 
de pobladores eran grandes. En 1973, último año de gobierno de la Unidad Popular, Manuel Castells (2005: p. 311-312) se preguntaba si existiría "una especificidad en las representaciones y prácticas de los pobladores como tales, y de qué especificidad se trata...".

Ni la fuerza del movimiento de pobladores, ni el debate sobre el quehacer de los intelectuales logrará sin embargo, revertir la evidencia de esta ciudad trizada que irremediablemente convive con el viejo ideario de la ciudad integrada. Santiago más se asemeja a un "conglomerado de subsistemas urbanos donde la imagen que prevalece es la de una serie de puntos de localización no relacionados... las distancias son largas... Incluso los profesionales, con una presumible mayor facilidad de pensamiento conceptual que el resto de la gente, tienen dificultades en visualizar la Región Capital como su hábitat... una gran parte de sus vidas se pasa dentro de un radio estrecho definido por el lugar de trabajo y su casa" (Friedmann $\&$ Necochea, 2005: p. 41-47). Junto a este modelo de ciudad archipiélago, crece el consenso en la coexistencia y el aumento de las "desigualdades sociales en este mismo Santiago" (Friedmann \& Necochea, 2005: p. 47).

A fines de los años ochenta, la ciudad trizada y segregada pareciera endurecerse y consolidarse. Ni los importantes procesos de modernización impulsados por la recientemente inaugurada red de Metro lograrán revertir esta imagen de ciudad desigual (Galilea \& Hurtado, 2005). A la histórica segregación territorial se superpone de forma creciente la segmentación social; imaginario que habla de la persistencia de una estructura social metropolitana polarizada. Contradicción entre una urbe que al mismo tiempo que se moderniza, conserva los históricos patrones de segregación territorial y a la que se superpone de forma creciente la segmentación social y el temor al otro.

Sin embargo, terminando el siglo XX, nuevos estudios advierten que a pesar de mantenerse las marcadas desigualdades sociales que ha traído la globalización económica a Chile, la escala geográfica de la segregación en Santiago podría estar retrocediendo, abriendo oportunidades inéditas y específicamente urbanas de integración social
(Sabatini, 2005: p. 420). Ello no impide, sin embargo, que junto a la consolidación y expansión urbana de Santiago se profundicen los anhelos y temores frente a esta ciudad trizada (Ducci, 2005: p. 481). El imaginario de ciudad atrincherada, pareciera derivar en nuevas formas de segregación espacial que producen quienes se encierran y ocultan mediante muros, rejas y privatización de las calles. Un imaginario que orienta hacia nuevas formas de protección y que modifica progresivamente el paisaje urbano, los viajes por la ciudad, los hábitos y la cotidianidad. En barrios populares los vecinos se organizan para cuidar la seguridad e impedir, incluso, la entrada de la policía. En barrios de sectores económicos más poderosos se establecen conjuntos residenciales y lugares de trabajo cerrados o con acceso rigurosamente restringido. Segregación física instituida por enclaves fortificados y muros simbólicos que los refuerzan. Una cultura de la protección sobrevigilada que se alía con un imaginario que se vuelve hacia el interior para satanizar la calle e idealizar la comunidad de iguales. Relato nostálgico de la celebración del ghetto (Sennet, 2001), que nos habla de procesos de desurbanización (García Canclini, 1997) y un imaginario que habla del olvido de los ideales de la modernidad urbana.

\section{El imaginario de la ciudad aldea / ciudad global}

Santiago tiene la característica de las grandes ciudades, pero en otro sentido que el de las grandes urbes europeas. Aquí, cada barrio es una aldea pequeña, y sus habitantes parecen haber olvidado que pertenecen, en conjunto, a una agrupación mayor... Esta vida local del barrio explica muchas cosas que no comprendemos a primera vista: la falta de vida en común de gran ciudad, por ejemplo; su aspecto triste y abandonado durante la noche; la falta de amory diversión colectivos. La verdad es que en Santiago todo ocurre 'puertas adentro'. Cada barrio es un pozo de promiscuidades e historias de toda indole que no afloran en la vida urbana".

B. Subercaseaux, Chile o una loca geografía, 1940.

Modernización entendida como globalización y participación en el mundo del consumo y sus 
artefactos. Identidad entendida como pertenencia a una aldea/comunidad en donde se ejercen lazos afectivos. Estos parecieran ser los dos polos de la cuestión urbana (De Certeau, 1996) en esta ciudad de profundas e históricas trizaduras.

Nuestra ciudad y nuestro país han convivido históricamente con un imaginario de país próspero que se desea y se realiza en una imagen moderna y atractiva más allá de las propias fronteras. Este fue el imaginario de Vicuña Mackenna, empecinado en convertir a Santiago en el París de América, extirpar el vicio y mejorar las condiciones de vida (principalmente de higiene) de las clases populares, prohibiendo la vagancia y embelleciendo el espacio público. Un Santiago tempranamente mestizado y fuertemente europeizado, cuya homogeneidad étnica pareciera no merecer duda alguna, y que acompaña un proyecto modernizador difundido a través de imágenes que se envían al exterior operando a modo de juego de espejos en la construcción de una identidad siempre esquiva del ser santiaguino. Un imaginario que nos ha acompañado históricamente desde la exposición universal de París en 1889, al traslado del Iceberg a Sevilla en 1992, para los 500 años del Descubrimiento de América (Norambuena, 2003).

El imaginario de ciudad de clase mundial coexiste sin embargo, con un campo imaginado residual y emergente que no siempre se condice con el imaginario de la ciudad translocal y global. Es el imaginario de la nostalgia comunitaria y bucólica, de la ciudad o barrio aldea con reminiscencias rurales y de tiempos lentos a la que sin embargo, se contrapone la ciudad global, la ciudad del consumo, de los tiempos rápidos, de la estética de la seguridad, de los artefactos urbanos (aeropuertos, carreteras y malls) y de los no lugares. (Augé, 1992)

"Las ciudades siguen esparciéndose por el territorio y, lo que es más importante, cuando se les pregunta a los residentes, la mayor parte de la población contesta que le gustaría tener una casita con jardín afuera” (Ducci, 2005: p. 481).

Es el imaginario del barrio-jardín, que paradójicamente iguala a los habitantes de esta ciudad:
"Es una imagen que recorre toda la escala social y así como los niños dibujan la cordillera como fondo permanente de sus paisajes, todos dibujan también su casa como la de un cuento infantil noreuropeo: techo rojo a dos aguas, ventanas con visillos, chimenea y un sendero curvo entre flores que va hasta la puerta de entrada. Desde las poblaciones con sitios de $100 \mathrm{~m}^{2}$ y $25 \mathrm{~m}^{2}$ construidos, hasta las grandes y complejas casas de las clases adineradas, el modelo básico es el mismo: un pabellón rodeado de jardín” (Palmer, 2005: p. 190).

Diversidad, segmentación y privatización eran rasgos previsibles de encontrar en estos relatos de la ciudad; ellos han llegado a ser inherentes a la vida contemporánea, pero que se alimenta de una obsesión nostálgica por la ciudad perdida; o para ser más rigurosos, con la ciudad deseada. Pobladores que añoran las prácticas solidarias del campamento; familias nostálgicas de sus barrios de la infancia y la vida bucólica; habitantes que guardan en su memoria los tiempos en que ir al centro era un viaje de asombro; relatos que vuelven una y otra vez al Santiago de antaño, una ciudad donde, según sus habitantes, primaba el sentimiento de una identidad común, de una comunidad.

Nostalgia casi mítica de una ciudad imaginada que más asemeja a una aldea que a la urbe moderna; a la comunidad (Gemeinschaft) que a la sociedad (Gesellschaft), pero que se constituye como el hilo de la trama del que escribía Armando de Ramón. Los relatos hablan de imágenes de ciudad, pero también de prácticas cotidianas que reactualizan la comunidad que alguna vez esta sociedad urbana fue o habría querido ser.

Imaginarios que conviven y se superponen, contradicción entre modernización y formas comunitarias, que en Santiago toman la forma de una ciudad privada, moderna, anónima y avasalladora frente a la localidad y/o el barrio como espacio del encierro, el encuentro y a veces la actoría local. Imaginarios que se anuncian en la tendencia creciente al abandono de la metrópoli como modo de vida urbano, ya sea por la recreación de nuevas formas de vida en los bordes de la ciudad, la salida hacia las regiones (tal como lo indica el último 
Censo 2002), o simplemente en la nostalgia de una ciudad y un modo de vida pasado.

\section{A modo de conclusión}

La lectura entrelíneas del libro Santiago en EURE. Huellas de una metamorfosis metropolitana: 1970/2000, nos anuncia que el viejo imaginario social de la utopía de la ciudad integrada, si bien conserva rasgos como la añoranza de una cierta calidad de vida, de la armonía con la naturaleza, el calor de las relaciones y la valoración del vecindario... en muchos de sus rasgos, este imaginario ha sufrido una metamorfosis que habla de una erosión o desgaste de sus viejos referentes. Pero, "lo nuevo -nos advierte Carlos de Mattos al final del libro-, si bien representa importantes cambios respecto a la metrópoli heredada, en lo esencial refuerza y profundiza tendencias preexistentes y, con ello, asegura que lo que existía siga existiendo" (2005: p. 542).

¿Cómo nos arreglamos entonces para vivir a la vez en la ciudad real y la ciudad imaginada? (García Canclini, 1997). Por cierto, todas las ciudades presentan una tensión entre lo visible y lo invisible, entre lo que se sabe y lo que se sospecha, pero la distancia es grande en nuestras ciudades de las trizaduras y la globalidad. Entre el colapso y la nostalgia (De Mattos, 2005), los imaginarios anuncian un cierto desconcierto para ubicar esta carta de navegación.

Sabemos que vivimos en la ciudad porque en ella habitamos, caminamos, transitamos, trabajamos, parimos, festejamos... Apropiación que se construye de los usos de su materialidad, pero también de los relatos e imaginarios que allí se construyen. Aunque "Santiago es una ciudad construida a pedacitos cuadrados como un tablero de ajedrez; y eso le quita perspectiva y vida... porque todo está previsto topográficamente" (Subercaseaux, 1940: p. 87), siempre habrá manera de desbordarla y transgredirla. Los imaginarios decíamos, como composiciones libres y autónomas que son, siempre encontrarán lugar para desbordar con sus fantasías esta trama rígida. En la urbe siempre habrá un espacio residual donde la soberanía del imaginario colectivo e individual podrá detonar. Por tanto, podríamos decir, que la distancia entre los modos de habitar y los modos de imaginar la ciudad son parte y condición de la condición del hombre moderno y urbano, del urbanita.

En este sentido, la ciudad difícilmente puede ser comprendida como el lugar del orden y la coherencia. Ella es el lugar, por definición, de la experimentación de la diferencia (Sennet, 2001), de la multiculturalidad (García Canclini, 1996) y también de la sobreabundancia y exceso de sentidos, de la sobremodernidad (Augé, 1992). La densidad de interacción y el intercambio acelerado es un rasgo inherente a ella. No es de extrañar entonces que la posibilidad de fijar o asentar los imaginarios y/o las identidades sea un ejercicio que carezca de sentido en un espacio social donde el movimiento, la flexibilidad y la capacidad de transformación y metamorfosis son condiciones para sobrevivir y moverse en ella.

No es ahí donde reside el riesgo de la vida urbana y sus imaginarios. Tampoco en las incongruencias $^{7}$ entre estos imaginarios, pues son justamente estos des-conciertos, estas distancias entre esquemas utópicos, entre imaginarios que no se encuentran, los mejores indicios de que esta sociedad aún imagina, inventa y se pregunta... En tiempos de modernización y globalización vertiginosa estos son imaginarios que tal vez no tengan por qué aunarse en una sola gran utopía, en un solo gran relato común, en una sola imagen de ciudad ideal.

El riesgo está en la imposibilidad de imaginar algún tipo de coherencia entre imaginarios diversos, de manera tal que nos ayuden a convivir de formas más amables en la ciudad. La desurbanización de las ciudades, la disminución del uso de los espacios públicos, la guetización, el amurallamiento interno, la inseguridad, la fragmentación y la segregación social amenazan con substituir el deseo por el miedo. Recluidos en sus hogares, los habitantes de Santiago han aprendido a temerle y cuidarse del contacto con la diversidad que constituiría justamente uno de los principales valores del modo de vida urbano. La ciudad se nos ha llenado de puertas que no se abren a la construcción de la alteridad en el movimiento

\footnotetext{
"Nos encontramos con tantas incongruencias que debemos reconocer que algo está fallando...” (Ducci, 2005).
} 
de la urbe. En una ciudad temerosa, de puertas y ventanas cerradas, de puentes cortados (Simmel, 1998), la construcción de imaginarios, de principios de identificación y diferenciación se vuelven entonces ejercicios peligrosos. El malestar de los habitantes de Santiago requiere ser comprendido justamente a la luz de estos imaginarios siempre abortados, de la hipertrofia de la memoria, de la desmovilización y deshistorización nostálgica de cuando éramos felices.

En este deseo de imaginar una ciudad distinta, la pregunta que se impone es cómo pasar de la vigilancia y el miedo al conocimiento e imaginario común; cómo pasar de la hipertrofia de la memoria al reconocimiento de la diversidad de imaginarios, de hojas de ruta que nos orienten hacia la ciudad ideal. ¿Cómo hacer que el olvido y la memoria hipertrofiada no nos gane lugar? ¿Cómo hacer para que estos imaginarios de las ciudades ideales hablen y orienten el quehacer de los habitantes de esta ciudad?

Los significados que alimentan esta ciudad imaginada no son lejanos constructos ajenos a la vida cotidiana, a los contextos históricos y a las grandes decisiones macroeconómicas. Por el contrario, la ciudad imaginada se construye y reconstruye desde la vida de todos los días. En una ciudad segregada como la nuestra, la construcción de mundos entre iguales pareciera poder levantarse como espacios de resistencias a las mutaciones de las estructuras urbanas y el mercado del suelo. Sin embargo, en un contexto de desigualdad, este tejido social a menudo no hace más que reproducir y reforzar las diferencias sociales y los procesos de exclusión y aislamiento en la ciudad.

En su libro Santiago de Chile, el historiador Armando de Ramón (2000) sugiere, a quienes buscan como él construir un relato coherente de la ciudad, abrir espacio a la historia de sus habitantes, de sus clases sociales, de sus desplazamientos, de sus miserias y grandezas. De Ramón intuye que la escucha y la observación cuidadosa de sus habitantes puede evitar que nos perdamos en la confusión que nos ofrece una historia del desarrollo urbano plagada de quiebres y rupturas. En una ciudad trizada, segregada, móvil, policéntrica, amurallada... las trayectorias de sus habitantes se ofrecen como una trama densa sobre la cual comenzar a descubrir y tejer el relato de nuestra ciudad.

Hacer hablar a los imaginarios es abrirse a la diversidad de sus formas, de sus imágenes y representaciones: la ciudad del obrero, la ciudad del vagabundo, la ciudad del abogado, la ciudad del político, la ciudad de la prostituta, la ciudad del poblador... Imaginarios que nos advierten que Santiago no es una sola ciudad y que no se construye, ni se la recorre, ni se la puede apropiar de una sola manera. Pero para construir la ciudad imaginada no bastan los imaginarios individuales y solitarios. Unificar expectativas, abrirse al reconocimiento colectivo, romper con el temor a la diferencia y la estigmatización del otro, democratizar la ciudad son condiciones esenciales para superar la nostalgia de la comunidad y la aldea; y para abrirse a la ciudad como espacio de la diferencia, del movimiento y de la diversidad. La ciudad imaginada de hoy habla del temor a la diversidad, a la diferencia y al ejercicio de la libertad que debiera ser la ciudad. Los imaginarios de esta ciudad de Santiago advierten de los riesgos de la renuncia al movimiento que la vida urbana nos ofrece, la renuncia al movimiento entre lo público y lo privado, entre lo común y lo propio, entre los iguales y los diferentes.

En un contexto de desigualdad y fragmentación social como el nuestro, la ciudad de hoy requiere junto a estos esquemas de sentidos y orientación que son los imaginarios, de espacios comunes y ciudadanos para poder plasmarlos, someterlos a debate y por ende, legitimarlos. Para que la polis no pierda lugar, los imaginarios deben poder hablar de estas ciudades ideales que no son, sino una crítica al orden social.

No puede haber afirmación ni construcción del imaginario como deseo colectivo sin una redefinición de las relaciones de alteridad. Sin puertas abiertas, no habrá modo de asentar y capitalizar estos imaginarios urbanos que crecen sumidos en lo que De Certeau (1996) llamó el movimiento opaco y ciego de la ciudad habitada. 


\section{Referencias bibliográficas}

Augé, M. (1992). Non-Lieux. Introduction a une anthropologie de la surmodernité. París: Seuil.

Baeza, M. A. (2000). Los caminos invisibles de la realidad social: ensayo de sociología profunda sobre los imaginarios sociales. Santiago: Ed. Sociedad Hoy - RIL.

Castoriadis, C. (1995). Los dominios del hombre: las encrucijadas del laberinto. España: Gedisa.

Castoriadis, C. (1998). Hecho y por hacer. Pensar la imaginación. Buenos Aires: Eudeba.

De Certeau, M. et al. (1996). La invención de lo cotidiano. Series en el oficio de la historia. México: Universidad Iberoamericana.

De Mattos, C. et al. (2005). Santiago en Eure: huellas de una metamorfosis metropolitana. 1970/2000. Santiago: Instituto de estudios urbanos y territoriales, Pontificia Universidad Católica de Chile.

De Ramón, A. (2000). Santiago de Chile. Santiago: Ed. Sudamericana.

Duby, G. (1972). Los tres órdenes o lo imaginario del feudalismo. Madrid: Taurus.

Franz, C. (2001). La muralla enterrada. Colombia: Ed. Planeta.

Galetovich A. (Ed.) (2005). Santiago, dónde estamos y dónde vamos. Santiago: CEP.
García Canclini, N. (1997). Ciudad invisible, ciudad vigilada. La Jornada Semanal, 89.

García Canclini, N., Castellanos, A. \& Rosas Mantecón, A. (1996). La ciudad de los viajeros. México: Grijalbo.

Merino, R. (1998) Santiago de memoria. Santiago: Editorial Planeta.

Orrego Luco, L. (1985). Casa grande. Santiago. Andrés Bello.

Rojas, M. (2006). El imaginario: civilización y cultura del siglo XXI. Buenos Aires: Prometeo Libros.

Sartre, J. P. (1986). L'Imaginaire. París: Folio Essais.

Sennet, R., (2001). Vida urbana e identidad personal. Barcelona: Península.

Silva, A. (1996). Rito urbano e inscripciones imaginarias en América Latina. Persona y sociedad, $10,106-115$.

Simmel, G. (1998). Las grandes urbes y la vida del espíritu. El individuo y la libertad. Ensayos de critica de la cultura. Barcelona: Editorial Península.

Subercaseaux, B. (1973). Chile o una loca geografía. Santiago: Editorial Universitaria.

Universidad Metropolitana de Ciencias de la Educación (2002 - 2003). Imaginario y memoria histórica. Dimensión histórica de Chile, 17-18. 